Original Research Paper

\title{
Fire Evaluation of RC Frames Strengthened with FRPs Using Finite Element Method
}

\author{
${ }^{1}$ Reza Salehi, ${ }^{2}$ Abbas Akbarpour and ${ }^{3}$ Armaghan Shalbaftabar \\ ${ }^{1}$ South Tehran Branch Islamic Azad University, Tehran, Iran \\ ${ }^{2}$ Department of Civil Engineering, South Tehran Branch Islamic Azad University, Tehran, Iran \\ ${ }^{3}$ Computational Science and Engineering, North Carolina A\&T State University, NC, USA
}

\begin{abstract}
Article history
Received: 08-09-2020

Revised: 12-09-2020

Accepted: 05-10-2020

Corresponding Author:

Reza Salehi

South Tehran Branch Islamic

Azad University, Tehran, Iran

Email: st_r.salehi@azad.ac.ir
\end{abstract}

\begin{abstract}
Reinforced Concrete (RC) structures may confront with extreme loading conditions. Sometimes, structures are not only under extreme loading such as earthquakes but also, they may be subjected to fire. Therefore, investigation of reinforced concrete structures which are the most common ones is essential. In this study, experimental RC frame is considered to validate in ABAQUS finite element software. RC frame is subjected to both earthquake and fire loading condition to assess the seismic behavior of structure under extreme conditions. FRP techniques is also consider evaluating the seismic behavior such as load capacity, ductility, energy absorption and stiffness. In this regard, two different approaches including reinforcing and wrapping are employed. In this research, the pattern of retrofitting and reinforcing are the novelty of this work. In fact, the effect of using steel bars, BFRP bars and sheets are evaluated. The new method for combination of steel-BFRP bars and different BFRP sheet's angle as divergence and convergence are investigated. After carrying out the loaddisplacement diagrams, the seismic parameters of RC frames are compared and the optimized method and model is presented.
\end{abstract}

Keywords: Reinforced Concrete (RC) Frame, Fire, FRP Bars and Sheets, Finite Element Method

\section{Introduction}

Reinforced Concrete (RC) structures are one of the most common infrastructures in the world. However, it has always been confronting with internal or external deterioration due to natural disaster like earthquake, flooding or even environmental problems (Asmari et al., 2017; Kodur and Agrawal, 2016; Lim et al., 2014; Sayyar Roudsari et al., 2020a; 2019b; 2019c; Tang and Saadatmanesh, 2003). Therefore, investigation of these structural members is vital (Fallahi et al., 2019; Sayyar Roudsari et al., 2019a; Yi et al., 2008). These evaluations have been done by so many researchers to find out the seismic effects on strength the structural capability (Bracci et al., 1997; Chandrasekaran et al., 2016; Crisafulli, 1997; Fanaie et al., 2015; Sayyar Roudsari et al., 2018). However, the reinforced concrete structures are also come across to extreme loading conditions like fire, impact loadings, explosion and so on (Huo et al., 2018; Lenwari et al., 2016; Li et al., 2015;
Liu et al., 2018; Mistri et al., 2016; Soleimani et al., 2019; Soleimani and Sayyar Roudsari, 2015; Soroushnia et al., 2011). These artificial or natural phenomena cause devastating consequences because the deficiency of RC structures. Using Fiber Reinforced Polymer (FRP) is one of the most common methods of retrofitting RC members (Gong et al., 2019; Qin et al., 2019; Soleimani and Sayyar Roudsari, 2019). It can be used to enhance not only capability of RC structure for seismic loads but also, employing FRP material is suitable for extreme loading conditions. Kodur et al. (2019) studied to find out the effect of high temperature properties on FRP material. His results indicated that the properties of temperature can have influence on FRP's performance. Fallahi et al. (2018) did analytical study to retrofit the RC frames using finite element software. The results showed that CFRP can enhance the load capacity of RC frames. Li et al. (2019a) experimentally evaluated the performance of post-fire on reinforced concrete frames. He tested four specimens under various loading 
conditions like in furnace chamber and quasi-static, respectively. The results presented that the fire exposure decreased the load capacity, stiffness and ductility. Hamoush et al. (2020) performed the experimental and numerical investigation on steel frame embedded with gypsum board wall. He tested the specimen under lateral cyclic loading condition and carried out the load0displacement results. In order to enhance the load capacity, he employed the grommet damping system. The results indicated that the frame and wall have better performances when the specimen was strengthen with dampers. Shah and Sharma (2017) investigated the effect of fire and spalling on the performance of RC columns. His results indicated that the confinement of $\mathrm{RC}$ column has an indispensable role in resistance of column. Sayyar Roudsari et al. (2020b) did numerical study on RC column to find out the effect of time on load capacity and stiffness of RC column during the fire load. He used ABAQUS software to define specific criteria for material properties and simultaneous fire and axial loading on RC column. The $600^{\circ} \mathrm{C}$ as fire load was applied on the column's surfaces for 10,15 and $20 \mathrm{~min}$. The validation of his work shows very good agreement with experimental results. Moreover, the time duration of fire caused a significant reduction of stiffness. On the other side, some researchers focused on the material properties behavior under fire conditions and evaluate the effect of water-cement ration, aggregate size and type, using the fiber cementitious, material from renewable source and so on (Ahn et al., 2016; Hamoush et al., 2019; Khaliq and Kodur, 2017; Ma et al., 2015; Zhang et al., 2016). Zhou and Wang (2019) evaluated the repairing of fire damaged RC members. He did some studies to find out the effect of both fire and axial load on the existing structures. His results showed that using FRP jacket is the most efficient method in improving RC member's behavior than Near Surface Method (NSM) or steel wrapping method. Based upon above, it is obvious that there are many researches on the area of RC members, fire and retrofitting. However, most of them are experimental works concentrating about the effect of only fire temperature or retrofitting with FRPs (Jiang et al., 2018; Kodur et al., 2012; Li et al., 2019b; 2019c; Raouffard and Nishiyama, 2016; Sasmal et al., 2011; Wang et al., 2007).

In this study, RC frame is modeled by ABAQUS software. The RC frame is loaded under concurrent pressure and fire loads for five different fire temperature and time. These frames firstly tested as steel reinforcement and load-capacity diagram are carried out. Then, two strengthening methods as reinforcing with basalt (BFRP) bars and wrapping with basalt sheets are deployed to evaluate the RC frame behavior. Eventually, the seismic behavior of each model is discussed and the optimized model is presented.

\section{Materials and Methods}

The base of this research is the experimental works of (Hemmati et al., 2016). The RC frame of his research is a combination of $24 \mathrm{MPa}$ concrete compressive strength High-Performance Fiber Reinforced Cementitious Composite (HPFRCC) for beam-column connection and $48 \mathrm{MPa}$ for other regions. In Fig. 1, the geometry, reinforcement and different concrete compressive area are shown. Also, Fig. 2 displays the actual loading condition in the laboratory.

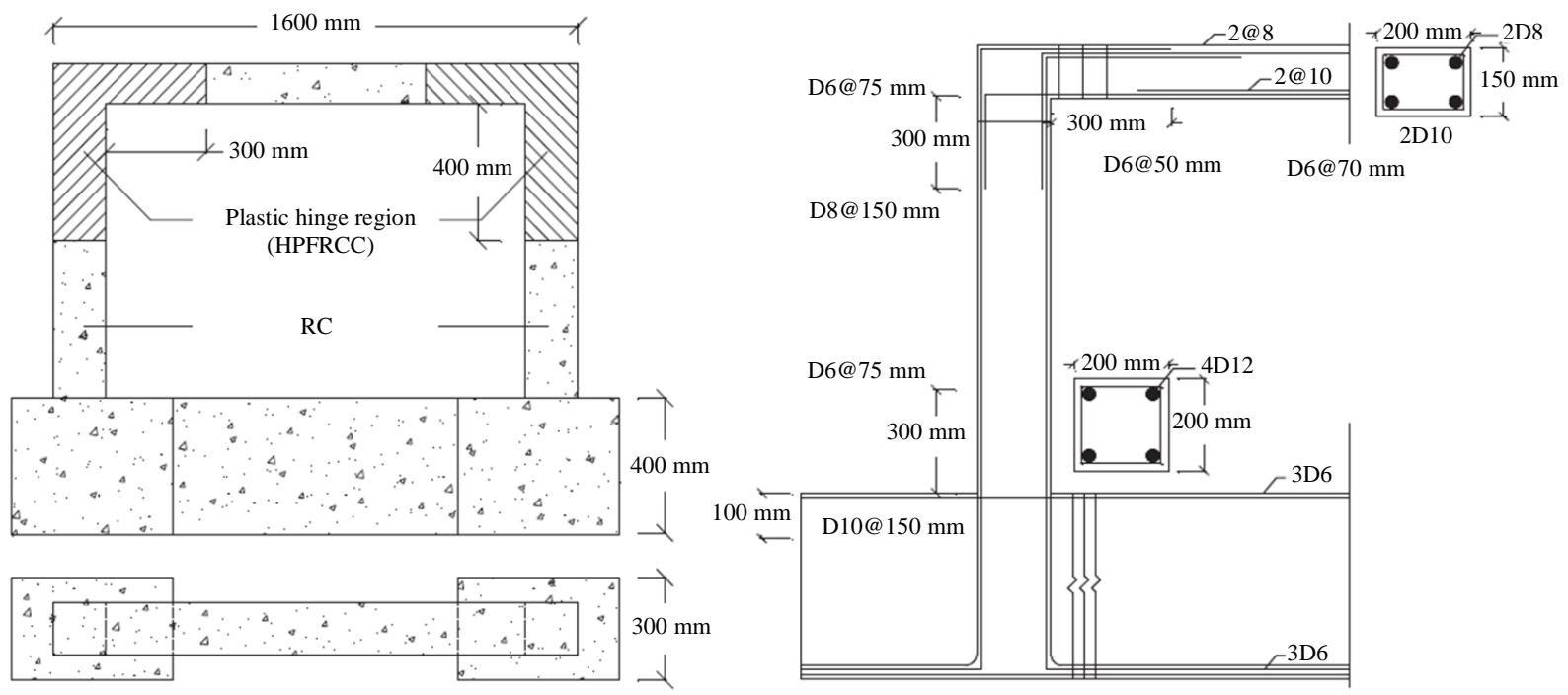

Fig. 1: Reinforcement details of RC frame 


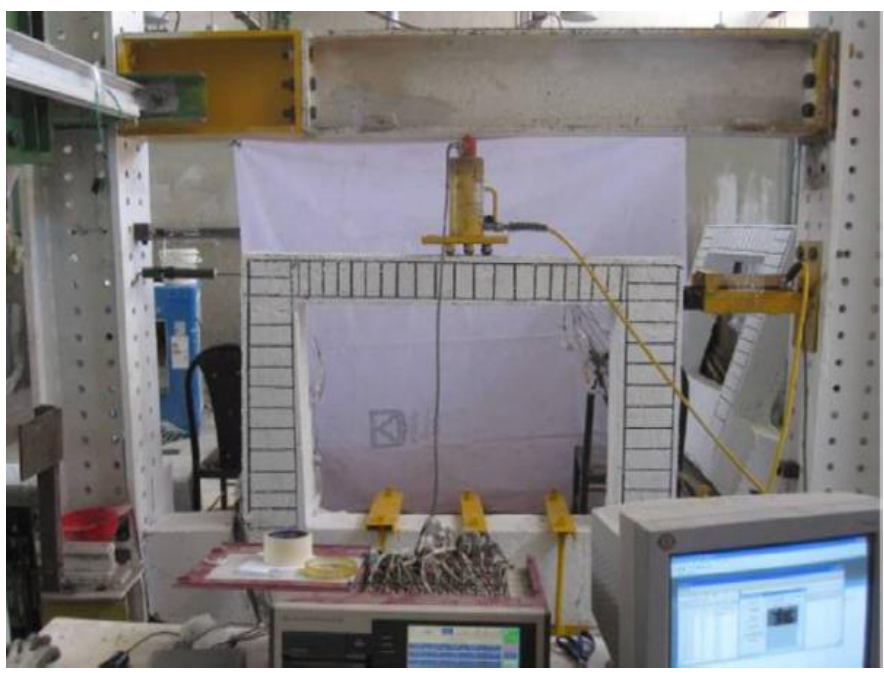

Fig. 2: Actual loading conditions of experimental tests (Hemmati et al., 2016)
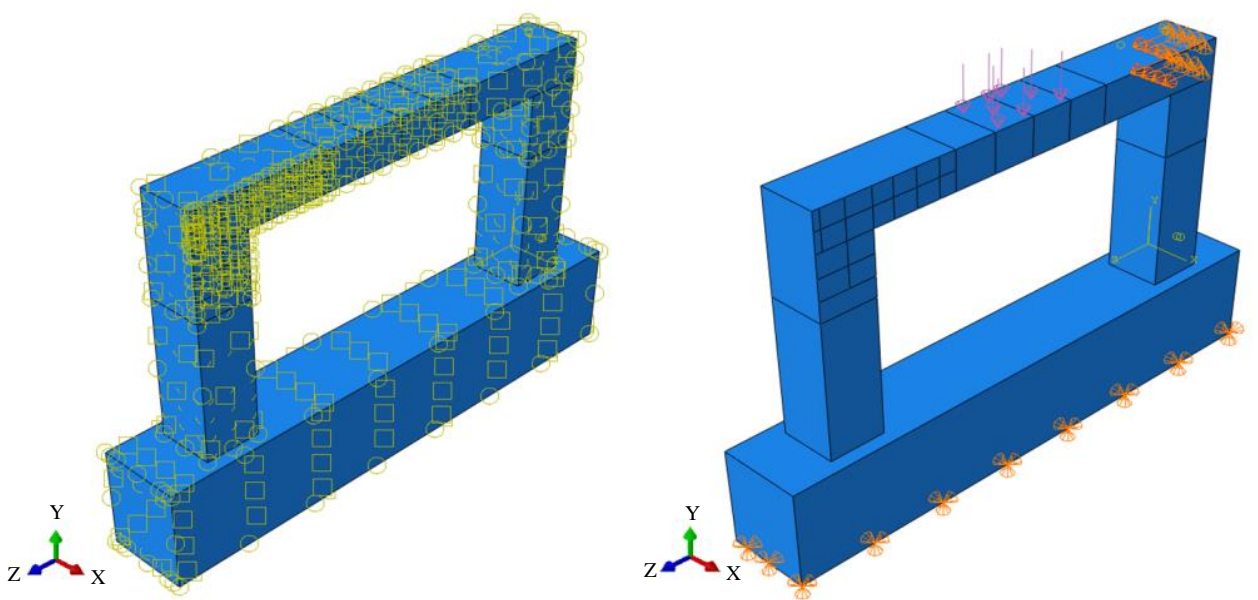

Fig. 3: Interaction and boundary condition modeling in ABAQUS

Table 1: Mechanical Properties of BFRP Sheets (Kheyroddin and Naderpour, 2008)

\begin{tabular}{llllll}
\hline $\begin{array}{l}\text { Tensile Strength- } \\
\text { Parallel of Layer }\end{array}$ & $\begin{array}{l}\text { Compressive Strength- } \\
\text { Parallel of Layer }\end{array}$ & $\begin{array}{l}\text { Tensile Strength- } \\
\text { Perpendicular of Layer }\end{array}$ & $\begin{array}{l}\text { Compressive Strength- } \\
\text { Perpendicular of Layer }\end{array}$ & $\begin{array}{l}\text { Longitudinal Shear } \\
\text { Strength (MPa) }\end{array}$ & $\begin{array}{l}\text { Transvers Shear } \\
\text { Strength (MPa) }\end{array}$ \\
\hline 550 & Direction (MPa) & Direction (MPa) & Direction (MPa) & 117.4 & 117.4 \\
\hline
\end{tabular}

\section{Finite Element Modeling and Validations}

There are two validations in this research; one for RC frame without fire (Hemmati et al., 2016) and other RC column under fire load. In order to validate the experimental, ABAQUS finite element software is employed (Fig. 3). The material properties of concrete are defined by Concrete Damage Plasticity Model (CDPM). Computing CDPM parameters as compressive and tensile strain-stress as well as its damages is done using (Roudsari et al., 2019). He did the state-of-the-art method for finding CDP parameters with higher accuracy using theoretical methodology and MATLAB toolbox. The module of elasticity for steel is $200 \mathrm{GPa}$ and yield stress is $400 \mathrm{MPa}$. The Basalt Fiber Reinforced Polymer (BFRP) is defined using Table. 1. Also, the module of elasticity for BFRP is $50 \mathrm{GPa}$ and ultimate stress and failure strain are considered 1095 and 2.19\%, in order. The Non-Linear Static Analysis is defined to apply appropriate boundary conditions. Moreover, the longitudinal and transvers bars are interacted with concrete using Embedded Region. The dead load above the beam is applied as pressure while the lateral load is subjected by Displacement Control. 8-node element 
using reduced integration (C3D8R) is used for solid concrete members and T3D2 is used as truss element for reinforcement. Also, the shell element is deployed for modeling CFRP sheets and the tie interaction is considered between concrete surface and CFRP. It should be noted that the CFRP sheet has $150 \mathrm{~mm}$ width and $2 \mathrm{~mm}$ thickness (one layer).

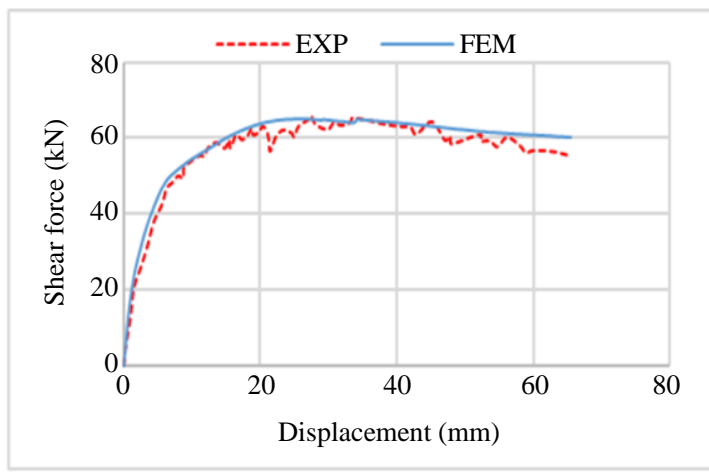

Fig. 4: Validation of experimental versus ABAQUS Software; without fire load

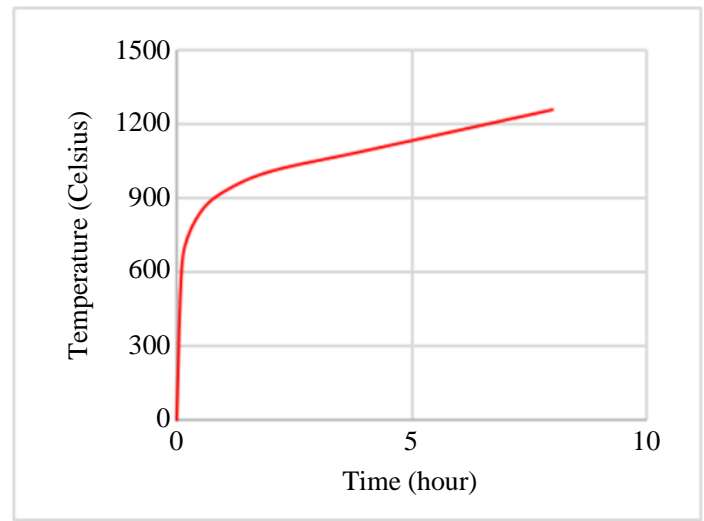

Fig. 5: Time-temperature diagram (ISO, 2019)

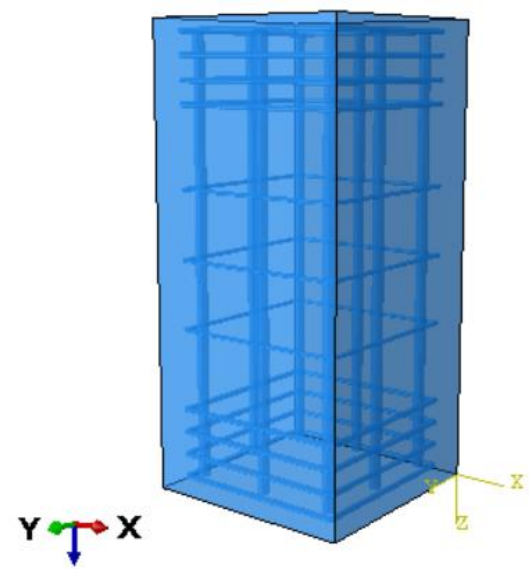

Fig. 6: RC column modeling under both fire and lateral load
In Fig. 4, the validation of $\mathrm{RC}$ frame without fire load is shown. Comparison of Finite Element Method (FEM) and experimental result indicates that the difference of load capacity is less than $2 \%$. After the accurate validation of RC frame, the fire should be validated, too. In order to validate the fire modeling, the experimental research of (Zhang et al., 2017). The column cross-section is reported $350 \times 350 \mathrm{~mm}$ and eight of $20 \mathrm{~mm}$ longitudinal bars and $10 \mathrm{~mm}$ as transvers bar diameter are used. The RC column is applied under lateral and fire loads. The maximum fire temperature is subjected to reach up to $900^{\circ} \mathrm{C}$. The fire is considered based on ISO-843 Standard which is displayed in Fig. 5 (ISO, 2019). It has to be mentioned that the modeling criteria is done like the RC frame validation. Also, the fire parameters which are done by (Roudsari and Abu-Lebdeh, 2019) is used for this numerical research. He used the conductivity and specific heat criteria for fire temperature. In the fire validation model, the Coupled-Temp Displacement (Transient) type of analysis is used. The RC column model is shown in Fig. 6.

In Fig. 7, the load-displacement diagram of second validation indicates the significant agreement of fire modeling by FEM as $214 \mathrm{kN}$ for FE output and 210 $\mathrm{kN}$ for experimental. It is obvious that the accuracy is about $2 \%$.

\section{Parametrical Study}

In this research, the RC frame is developed for analyzing under $200,400,600,800$ and $1000^{\circ} \mathrm{C}$. There are three categories including:

- $\quad \mathrm{RC}$ frame reinforcing with steel bars

- $\quad \mathrm{RC}$ frame reinforcing with BFRP bars

- $\quad \mathrm{RC}$ frame wrapped with BFRP sheets

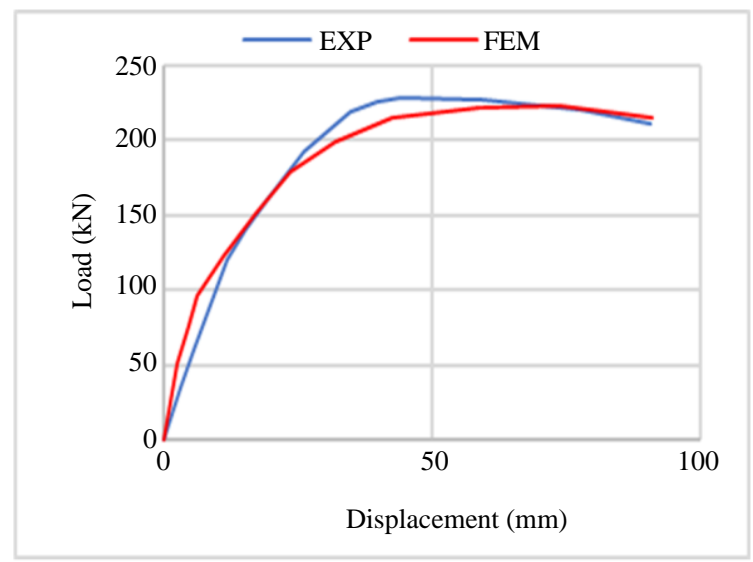

Fig. 7: Validation of experimental test; RC Column - versus ABAQUS under fire 
In fact, after validations, the behavior of $\mathrm{RC}$ frame under five different fire loads is investigated. The bottom line is the pattern of reinforcement. In BFRP bars modeling, in one model, the longitudinal bars of the beam are BFRP and steel bars are used for columns and slab. Another pattern is indicated that all longitudinal bars in both beam and column are reinforced by BFRP bars. In Table 2 and 3, the model's description of retrofitting patterns is shown. Also, Fig. 8 presents the assembly and interaction of $\mathrm{RC}$ frame. The initial fire temperature is zero and the maximum target one depends upon the fire temperature, for instance for $200^{\circ} \mathrm{C}$, it should be 200 . Also, the Specific Heat is considered 5700 for bars, 6000 for BFRP sheets and 1000 for concrete using Constant Volume criteria. The range of conductivity for FRP bars and layout are 0.003-0.0057 and 0.035-0.006, respectively. The conductivity for steel bars is 0.040.0518 and the specific heat is 5255 . The conductivity parameters for concrete is $0.0005-0.00114$. The Hashin Damage parameters are used to define the tensile and compressive behavior of FRP layout (the longitudinal tensile strength is $1278 \mathrm{MPa}$ and its elasticity modulus is $46000 \mathrm{MPa}$ ). Also, the Max Allowable Temperature Change Per Increment is applied $10^{\circ} \mathrm{C}$. In the interaction module, the Surface Film Condition as the Film Coefficient and Sink Temperature are considered 0.01 and 25, respectively. The lateral and pressure loading are considered as the same as validation model. In the loading module also, the Predefined Field is created to make environment temperature of Concrete Frame by applying $25^{\circ} \mathrm{C}$. The fire load is utilized by choosing Other/Temperature from Boundary Condition, applying at the inside surface of frame. Each temperature has its own amplitude using Fig. 5. Also, the Heat Flux is applied "10" for all elements. Figure 9 demonstrates the temperature, pressure and lateral displacement loading conditions of RC frame. Eventually, in the term of meshing criteria, the mesh study is used to verify the mesh seed size. Also, the family type of element's mesh is Coupled-Temperature-Displacement (Fig. 10).

Table 2: Models description details and names

\begin{tabular}{ll}
\hline Names & Description \\
\hline M-0 & Reinforced by Steel bars without Temperature Loading \\
M-200 & Reinforced by Steel bars under 200 Celsius Degree Loading \\
M-400 & Reinforced by Steel bars under 400 Celsius Degree Loading \\
M-600 & Reinforced by Steel bars under 600 Celsius Degree Loading \\
M-800 & Reinforced by Steel bars under 800 Celsius Degree Loading \\
M-1000 & Reinforced by Steel bars under 1000 Celsius Degree Loading \\
FB-C45B90 & Strengthening with BFRP, Column 45-degree, Beam 90 degree \\
FB-C45B45 & Strengthening with BFRP, Column 45-degree, Beam 45 degree \\
FB-C0B45 & Strengthening with BFRP, Column 0-degree, Beam 90 degree \\
F-BB-Total & Reinforcing by BFRP bars in both Beam and Column \\
F-BB-Beam & Reinforcing by BFRP bars in the Beam \\
F-CB-Beam-Bot & Reinforcing by CFRP bars in the Tensile zone of the Beam \\
\hline
\end{tabular}

Table 3. Geometry details of retrofitting pattern of rc frames

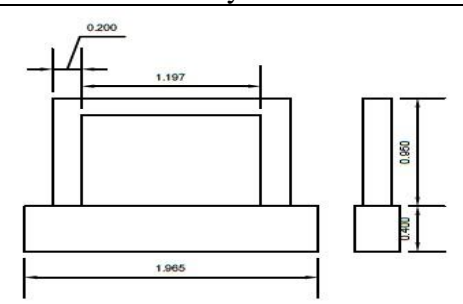

Original RC Frame

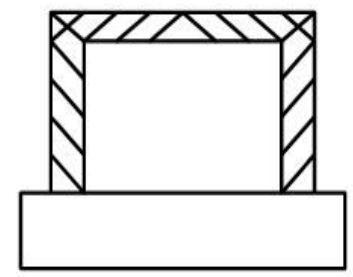

Model 2: The layout direction for column and beam is 45 degrees.

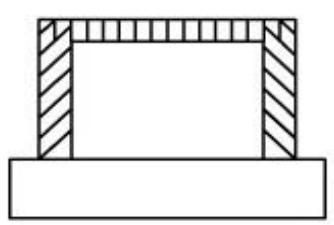

Model 1: The layout direction for column and beam is 45 and 90 degree, respectively.

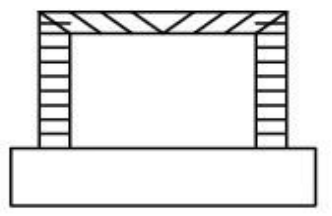

Model 3: The layout direction for column and beam is 0 and 45 degree, respectively. 


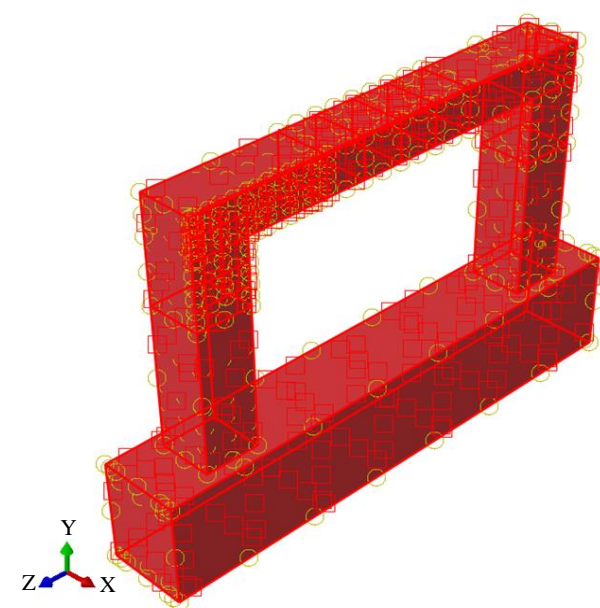

Fig. 8: Assembly and Interaction of RC frame in ABAQUS

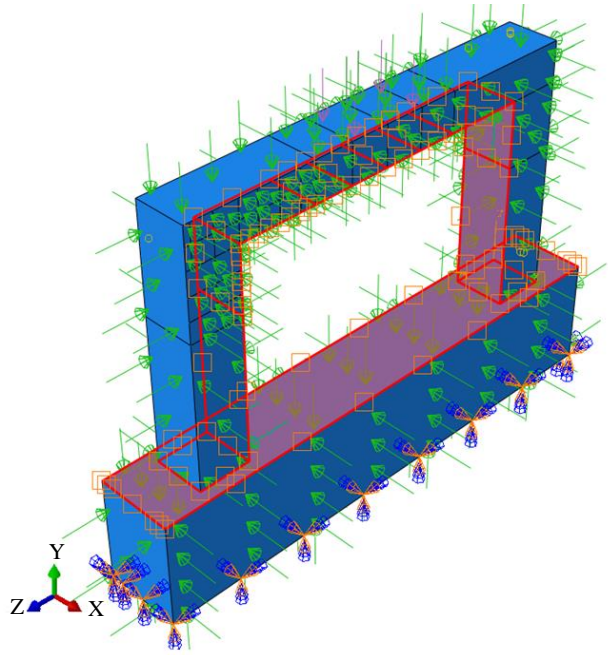

Fig. 9: Temperature, pressure and lateral displacement loading conditions in ABAQUS

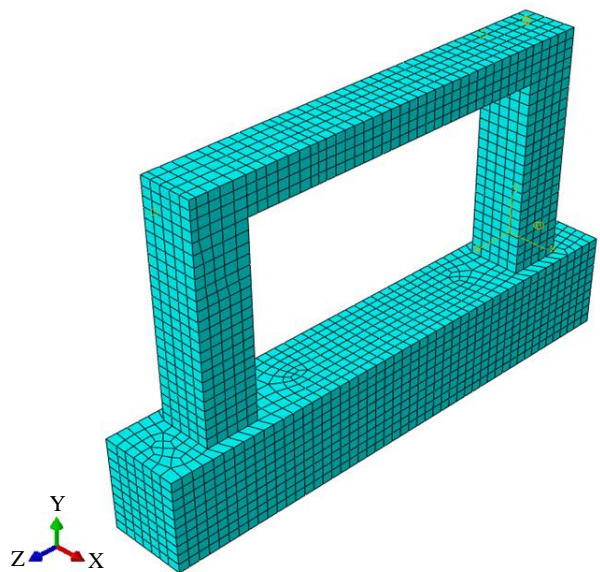

Fig. 10: Meshing in ABAQUS

\section{Results and Discussion}

In this section, the load-displacement diagrams of parametrical studies are shown. In Fig. 11, the loaddisplacement of frame reinforced with steel bars under different fire load is shown. As it can be seen, M-0 which is not under fire load, has the maximum load capacity and by increasing the temperature, the load capacity is reduced. Figure 12 to 16 present the effect of using Basal Fiber Reinforced Polymer (BFRP) bars in frame. In Fig. 12 and 13, it is seen that models reinforced with steel bars have as the same capability as BFRP bars. However, due to the fact that module of elasticity for steel is four time bigger than BFRP, the M-200 and M400 have better performance in elastic area. Comparison of Fig. 14 to 16 shows by increasing the temperature from 600 to 1000 Celsius Degree, the steel bars tend to lose the stiffness. In fact, M-600, M-800 and M-1000 smoothly reduced the strength and at the $1000^{\circ} \mathrm{C}$, it completely failed. Moreover, looking at model F-BBTotal and F-BB-Beam (Table 2), presents that using

BFRP totally has higher load capacity than using it only on beam area. The results of retrofitting by BFRP sheets (Table 3) shows the good performance of BFRP wraps in increasing load capacity of models under extreme fire (Fig. 17 to 21). In fact, the BFRP sheets avoid the collapsing issue even in $1000^{\circ} \mathrm{C}$. In this regard, the unique method of wrapping in this research is discussed, here. As it can be seen in the angle of sheets has a vital effect in seismic parameters of RC frame. As a case, FB-C45B90 model (column 45 and beam 90 degree) has the highest capability among all wrapping methods. In Fig. 17 to 19, when column of RC frame retrofitted by 45 degree (FB-C45B90 and FB-C45B45) is better than third pattern (FB-C0B45). Comparison of FB-C0B45 and FB-C45B45 which the difference is column's wrapping angle shows that 45-degree angle for BFRP sheets also has higher performance. In Fig. 20 and 21 , the load capacity of retrofitted models compared with model with only steel bars (M-800 and M-1000) declared that not only this system avoid collapsing of structure which is clear in M-1000 but also, it increase the maximum load capacity in 800 and $1000^{\circ} \mathrm{C}$, too.

\section{Discussion of Parametrical Study}

In this section, the seismic behavior like ductility, stiffness, load capacity and seismic factor $(R)$ have been presented. The ductility factor is computed by dividing the maximum displacement $\left(\Delta_{u l t}\right)$ on the displacement corresponding to yield force $\left(\Delta_{y}\right)$. Equation (1.) explains the ductility formulation (Sayyar Roudsari et al., 2020b):

$\mu=\Delta_{u l t} / \Delta_{y}$

Also, the stiffness is calculated using loaddisplacement diagram as the division of yield load 
(Sayyar Roudsari et al.) by yield displacement $\left(\Delta_{y}\right)$, Equation (2):

$E=V_{y} / \Delta_{y}$

Eventually, the seismic factor $(R)$ is defined by multiplication of strength reduction factor $\left(R_{u}\right)$ by strength enhancement factor $\left(R_{S}\right)$ Equation (3):

$R=R_{u} \times R_{s}$

In the Equation 3. the strength reduction factor $\left(R_{u}\right)$ is regarding the maximum load if the structure's behavior remains in elastic zone; $\left(\left(V_{e l}\right)\right.$ over the yield load (Sayyar Roudsari et al.)) Equation (4):

$R_{u}=V_{e l} / V_{y}$

And, strength enhancement factor $\left(R_{S}\right)$ is computed by the yield load (Sayyar Roudsari et al.) divides by the load at the first plastic hinge $\left(V_{s}\right)$ :

$R_{s}=V_{y} / V_{s}$

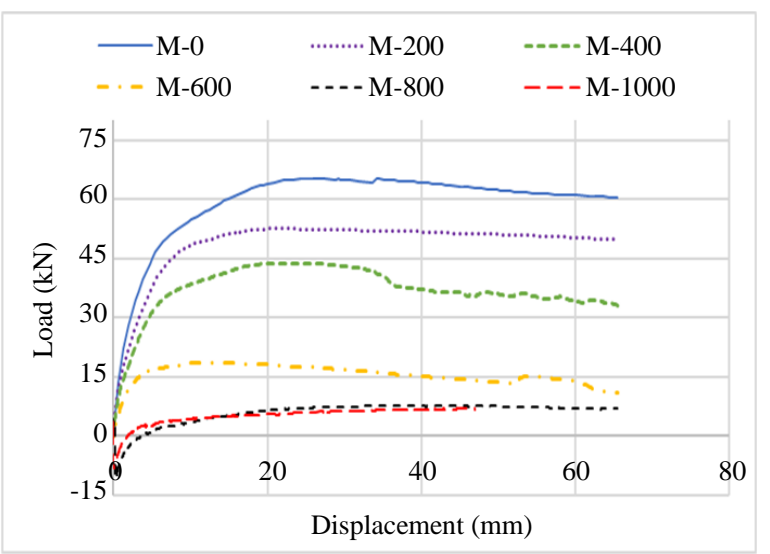

Fig. 11: Load displacement diagram for model with steel bars under different temperature Loading

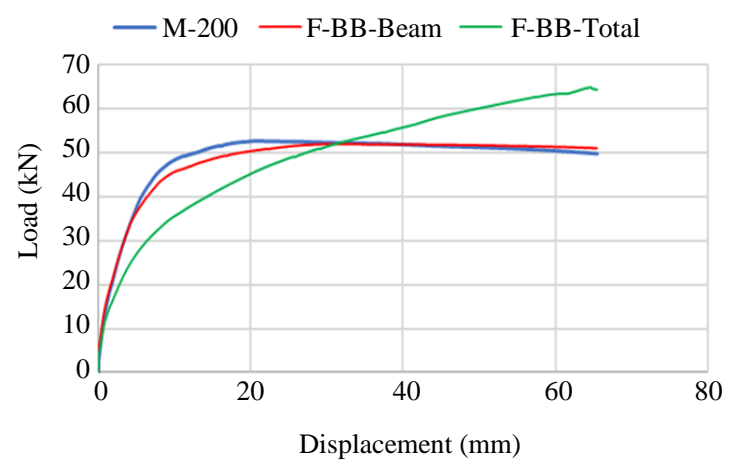

Fig. 12: Load displacement diagram BFRP bars - model under 200 Celsius degree

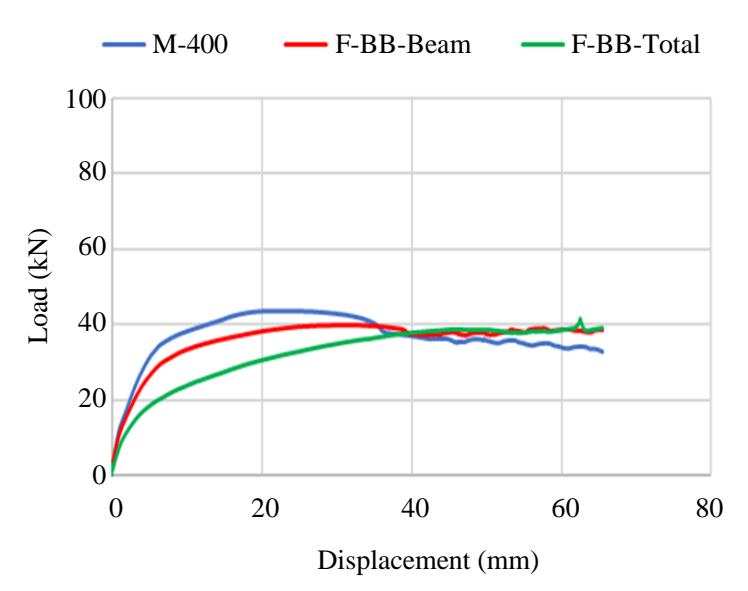

Fig. 13: Load displacement diagram BFRP bars - model under 400 Celsius degree

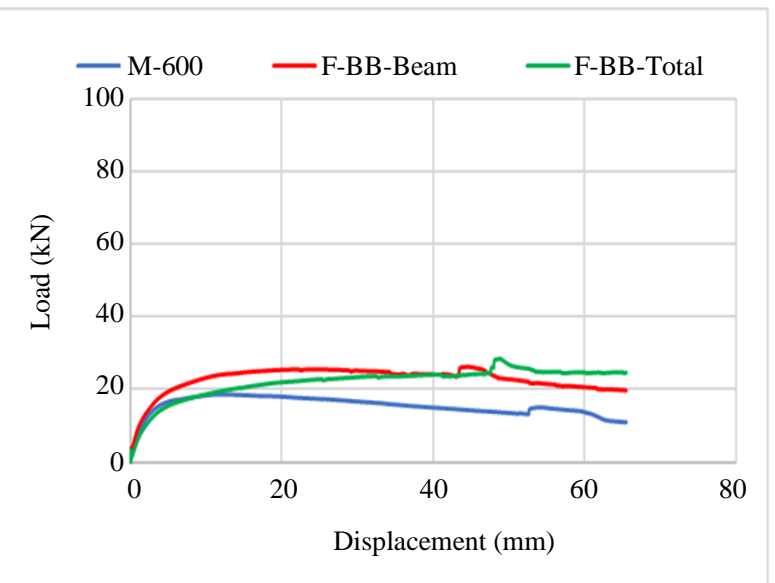

Fig. 14: Load displacement diagram BFRP bars - model under 600 Celsius degree

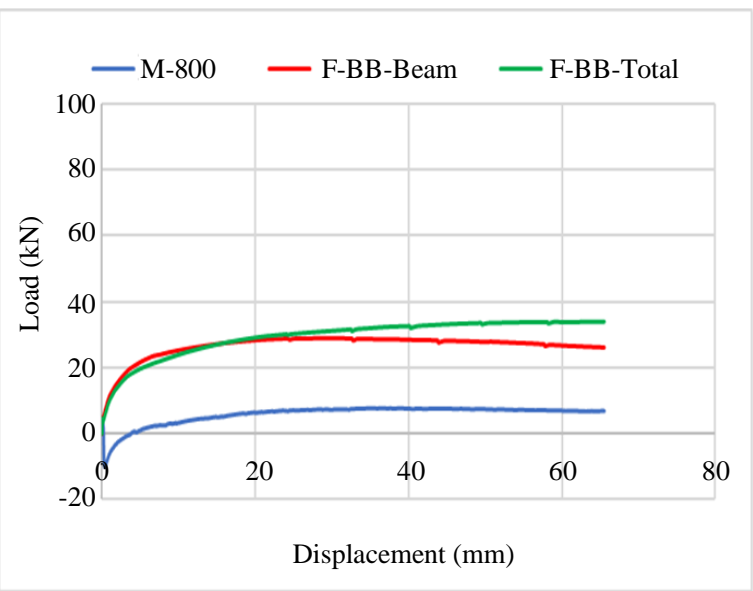

Fig. 15: Load displacement diagram BFRP Bars - model under 800 Celsius degree 


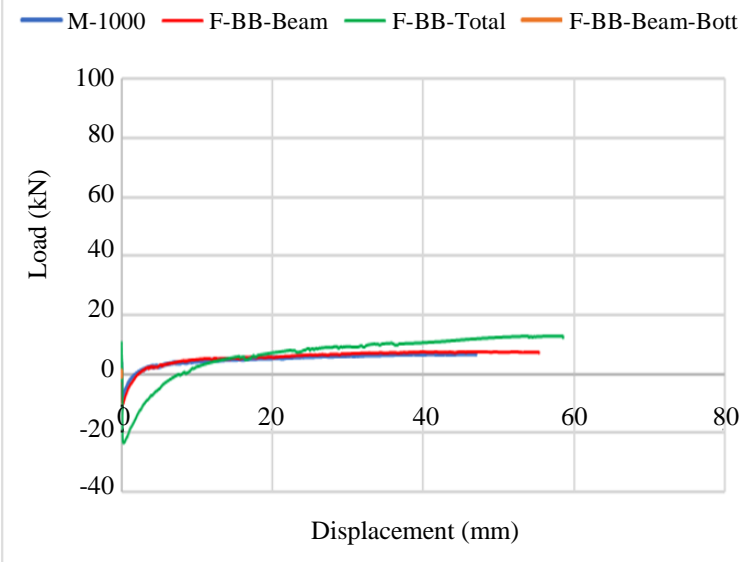

Fig. 16: Load displacement diagram BFRP bars - model under 1000 Celsius degree

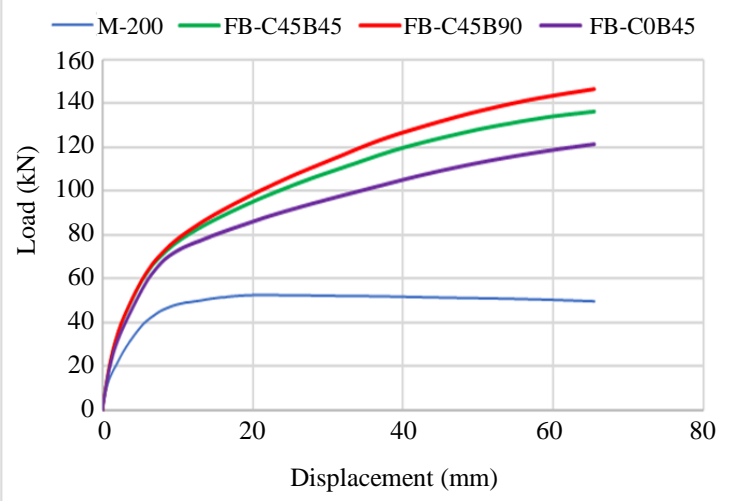

Fig. 17: Load displacement diagram retrofitted by BFRP Sheet, models under 200 Celsius degree

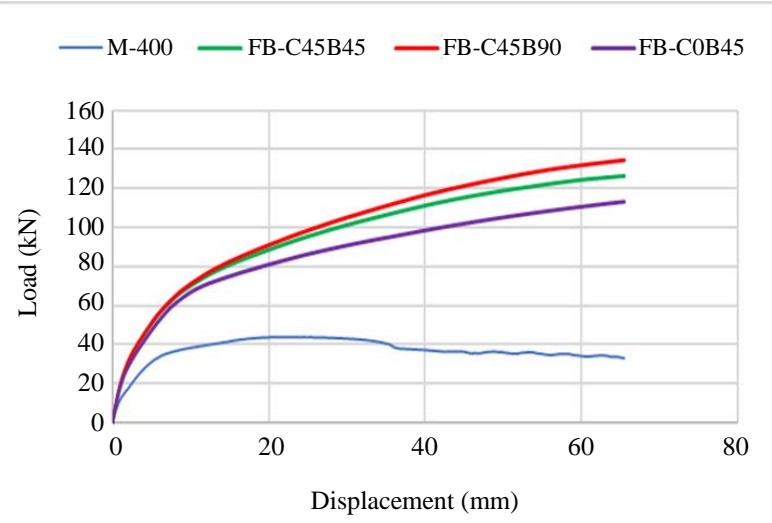

Fig. 18: Load displacement diagram retrofitted by BFRP sheet, models under 400 Celsius degree
- M-600 - FB-C45B45 - FB-C45B90 - FB-C0B45

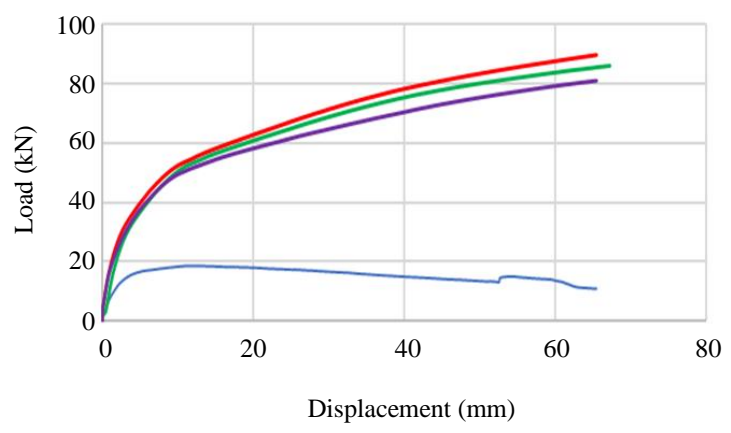

Fig. 19: Load displacement diagram retrofitted by BFRP sheet, models under 600 Celsius degree

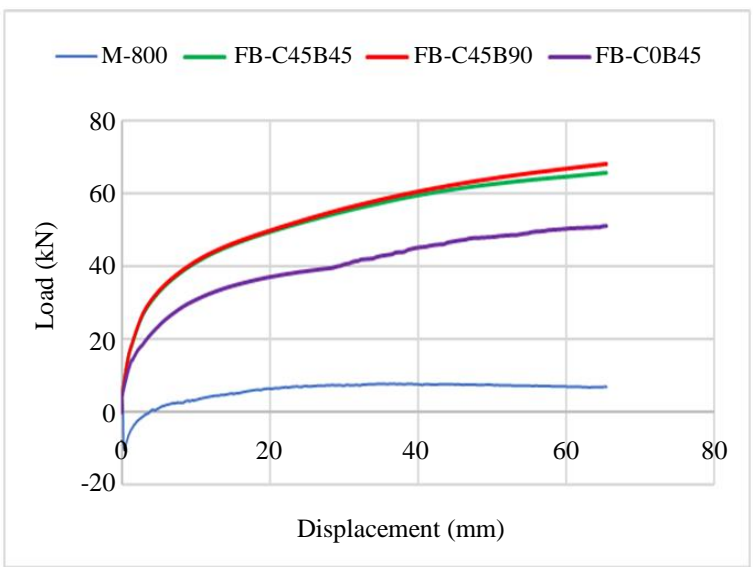

Fig. 20: Load displacement diagram retrofitted by BFRP sheet, models under 800 Celsius degree

- M-1000 - FB-C45B45 — FB-C45B90 - FB-C0B45

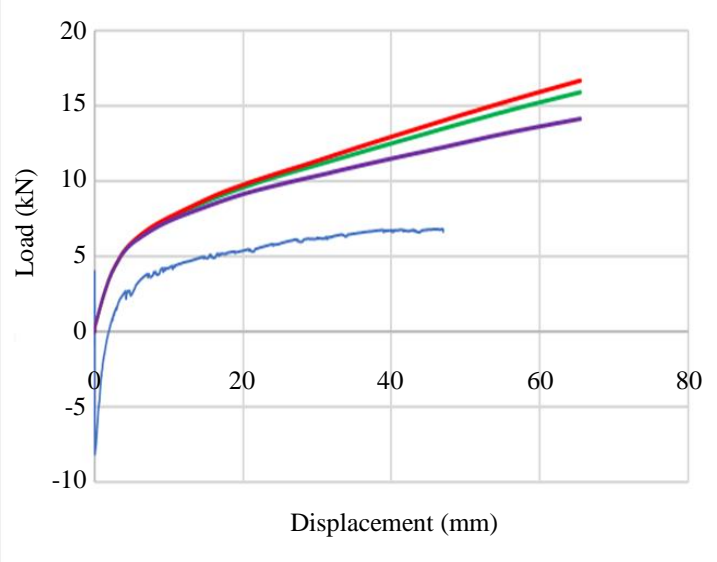

Fig. 21: Load displacement diagram retrofitted by BFRP sheet, models under 1000 Celsius degree 
In Fig. 22 to 26, the load capacity of all models is shown. In Fig. 22 comparing M-0 with M-200 shows that the $\mathrm{RC}$ frame has a reduction of load capacity from 65.25 to $52.58 \mathrm{kN}$. In models reinforced with BFRP bars (F-BB-Total), it is obvious that when BFRP bars are employed for all longitudinal bars, it has almost the same capacity as M-0 (without fire load). Comparison Fig. 23 and 24 indicates that the retrofitting method by BFRP sheets can enhance the load capacity of RC frame. On the other side, the comparison of each model with specific loading condition has still higher value than the original $(\mathrm{M}$ series). In other word, model like FB-C45B90 under $400^{\circ} \mathrm{C}$ has load capacity value about $134 \mathrm{kN}$ while the same model capacity under $600^{\circ} \mathrm{C}$ is about $90 \mathrm{kN}$. In Fig. 24 and 25 , in $1000^{\circ} \mathrm{C}$ cause the collapsing of $\mathrm{RC}$ frame which the highest value is belong to retrofitted model busing FB-C45B90 pattern. In Fig. 27 to 31, one of the most important seismic parameters as stiffness are shown. In the Fig. 27 to 29 and comparing BFRP bars specimens show that using BFRP bars only in beam has better performance of stiffness. In this regard, F-BB-Beam model under 200, 400 and $600^{\circ} \mathrm{C}$ has the stiffness value about $19.8,17.5$ and $12 \mathrm{GPa}$, respectively. When F-BB-Total models are compared, although stiffness is even less than using the steel bars. The reason of this issue goes back to the lower module of BFRP bars. On the other side, it can be presented now, when the combination of BFRP (in beam) and steel bars (columns) are used, the stiffness is higher than other reinforcing technique. The reason is that when steel or BFRP bars embedded in both beam and columns, the strong-weak beam and column phenomena happens. This issue causes the RC columns failed before beam's failure. Therefore, using BFRP bars with lower elasticity modulus and higher ultimate stress improved the stiffness of RC frame.
Moreover, comparing Fig. 30 and 31 show that there is a significant reduction of stiffness after $800^{\circ} \mathrm{C}$. Models under $1000^{\circ} \mathrm{C}$ in Fig. 31 approves this issue when the M-0 (20.76 GPa) compared with M-1000 (1.7 GPa), F-BB-Beam (2.6 GPa), FB-C45B90 (1.8 $\mathrm{GPa})$ and F-BB-Beam-Bott (3.75 GPa). Now, the important aspect is that when using steel bars on compressive side of beam and BFRP on the tensile ones has the best performance of strengthening models under $1000^{\circ} \mathrm{C}$. In Fig. 32 to 36 , the ductility factor is shown. Based on these results, the models reinforced with only steel bars have more ductility than others up to $400^{\circ} \mathrm{C}$. Since then, the combination of steel and BFRP bars have higher value either in reinforcing or wrapping models. In this case, F-BBBeam has a ductility factor on about 21.8, 29.77, 32.7, 43.67 and 18.45 under 200, 400, 600, 800 and $1000^{\circ} \mathrm{C}$. An interesting point is for F-BB-Beam-Bott model under $1000^{\circ} \mathrm{C}$ which has the ductility value more than 20. Comparing Fig. 35 and 36 shows that the most critical part of RC frame under extreme fire load $\left(800\right.$ and $\left.1000^{\circ} \mathrm{C}\right)$ is the tensile part of the beam due to weakness of the beam. So, adding BFRP bars only on the tensile area of beam can increase the ductility of whole system. In Fig. 37 to 41, the seismic factor of RC frame is shown. As it can be seen, the seismic factor of models retrofitted with BFRP sheets is higher than reinforcing method. For instance, the seismic factor of FB-C45B90 compared with F-BBBeam (optimized method) is about 5.6 and 4.21 under $200^{\circ} \mathrm{C}$, while this value for $600^{\circ} \mathrm{C}$ is 4.17 and 2.37 . On the other side, it can be seen that there is a sequence in retrofitting models indicates that $\mathrm{FB}$ C45B90, FB-C45B45 and FB-C0B45 have the highest to the lowest seismic value, in order. Furthermore, FB-C45B90 has the best performance of improving the seismic factor during the fire load.

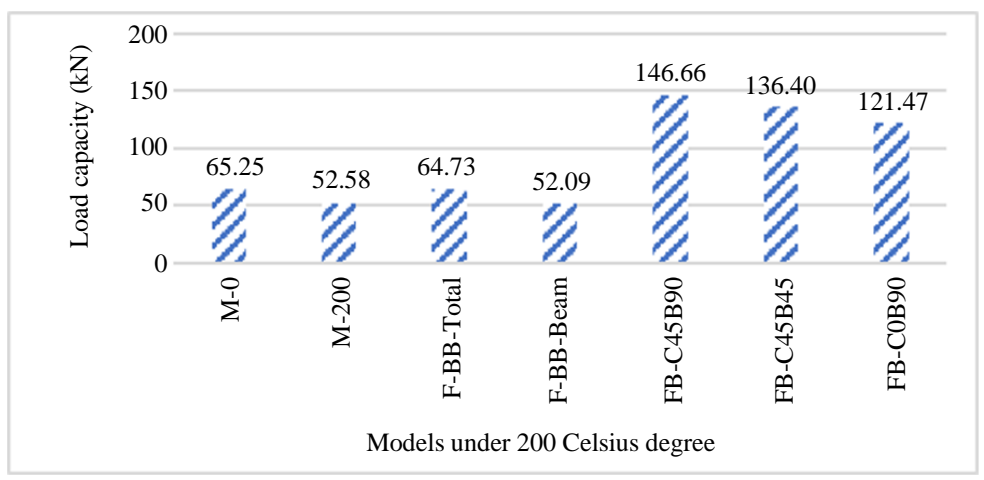

Fig. 22: Comparison of load-capacity - 200 Celsius degree 


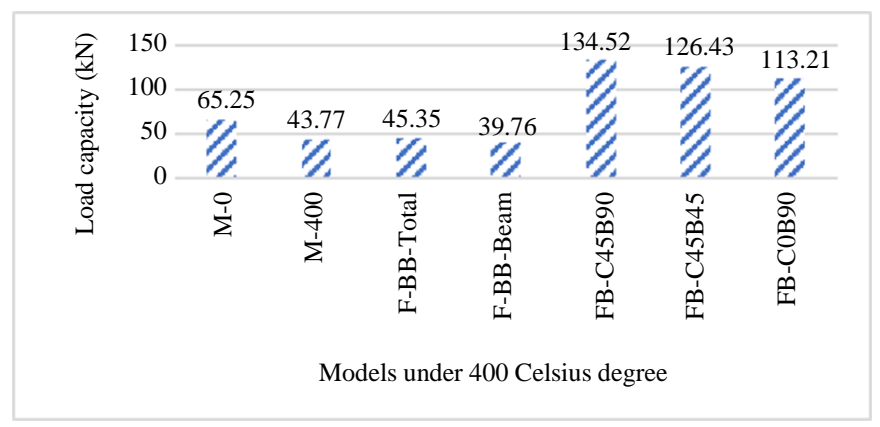

Fig. 23: Comparison of load-capacity - 400 Celsius degree

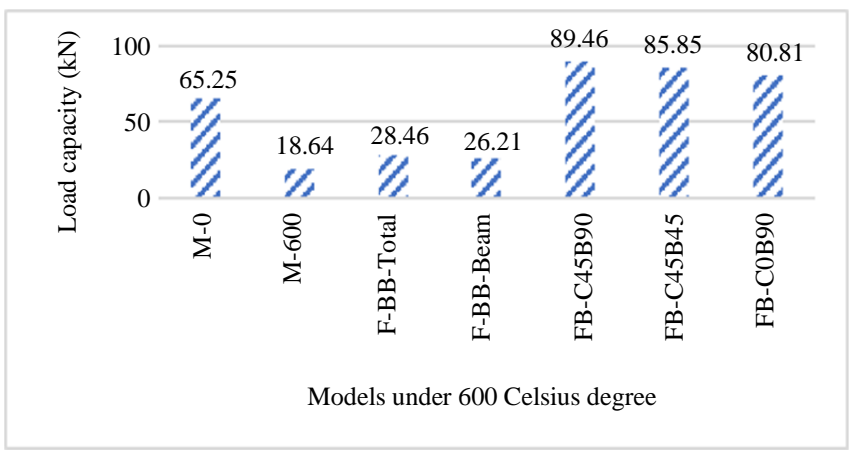

Fig. 24: Comparison of load-capacity - 600 Celsius degree

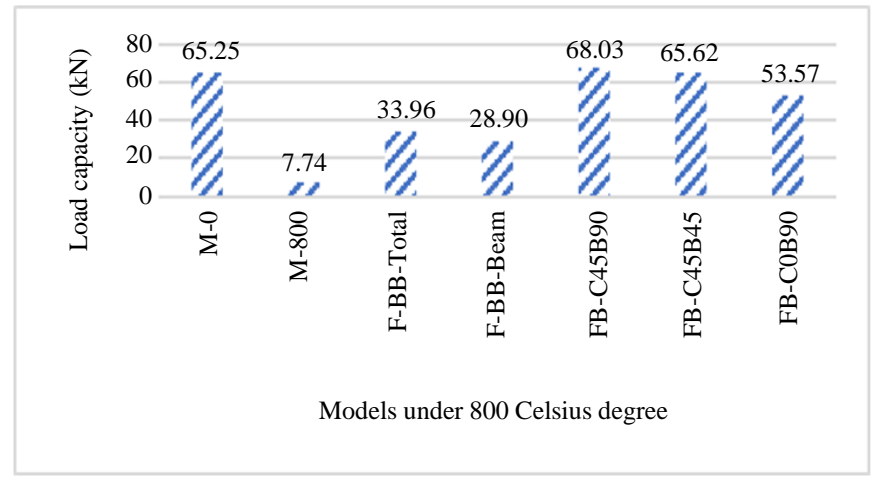

Fig. 25: Comparison of load-capacity - 800 Celsius degree

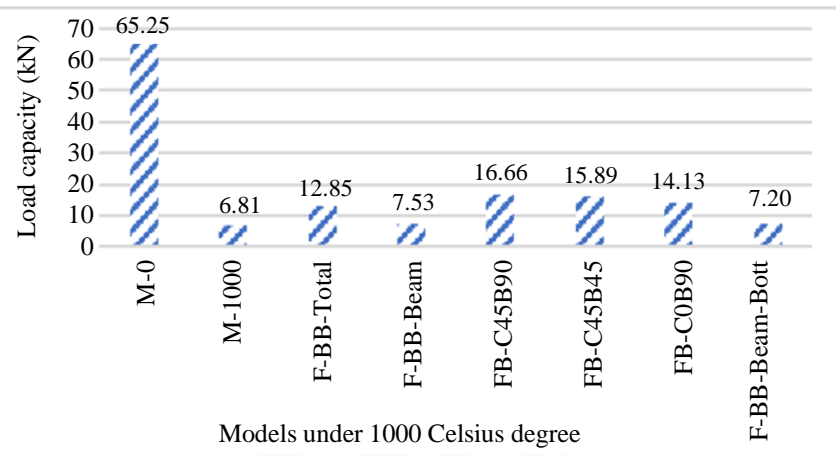

Fig. 26: Comparison of load-capacity -1000 Celsius degree 


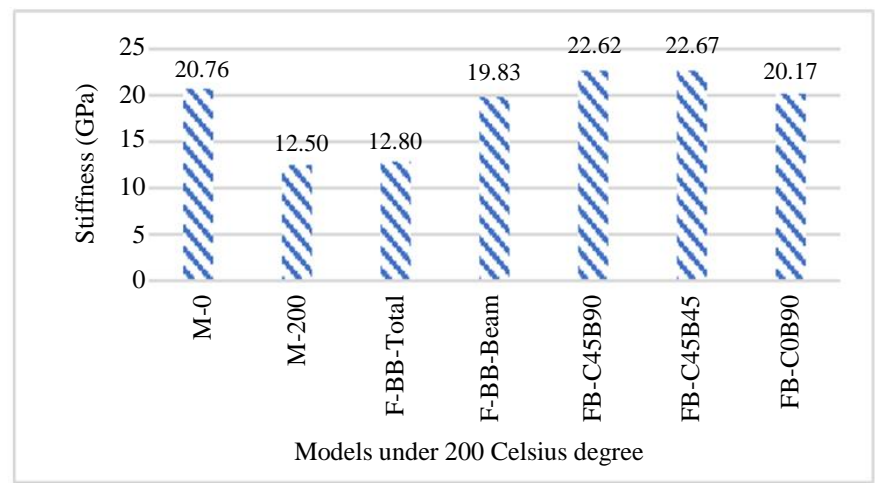

Fig. 27: Comparison of Stiffness-200 Celsius Degree

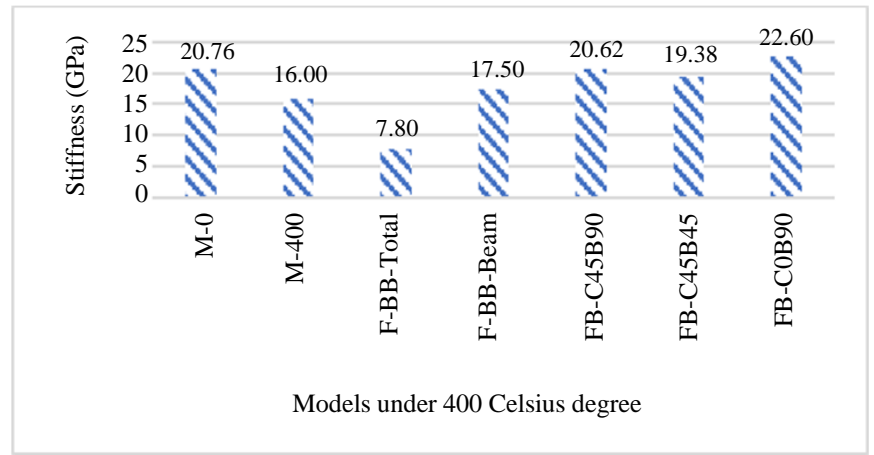

Fig. 28: Comparison of stiffness -400 Celsius degree

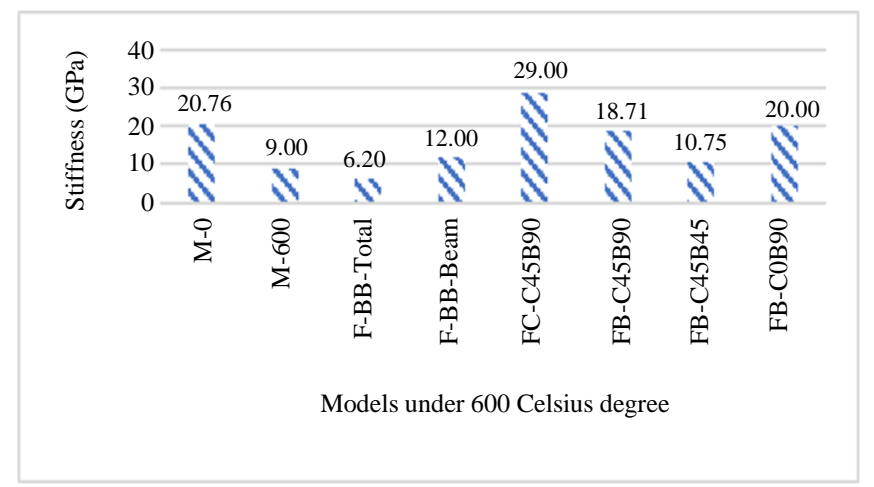

Fig. 29: Comparison of stiffness -600 Celsius degree

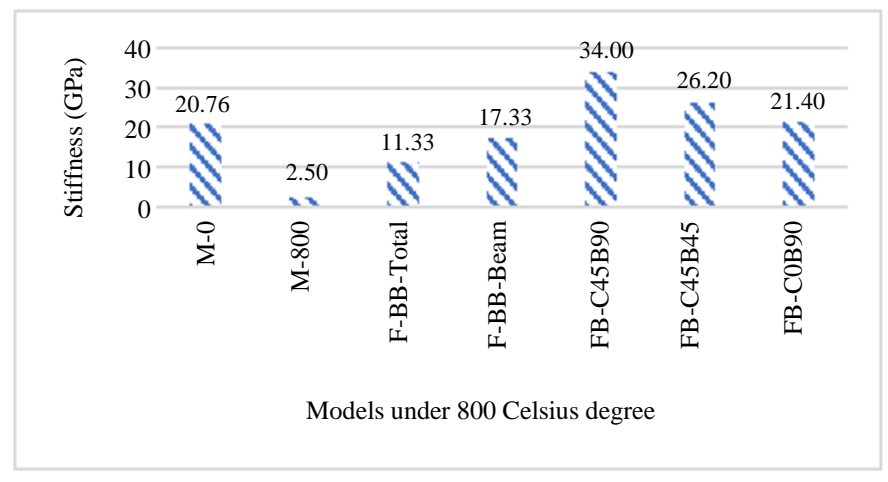

Fig. 30: Comparison of stiffness - 800 Celsius degree 


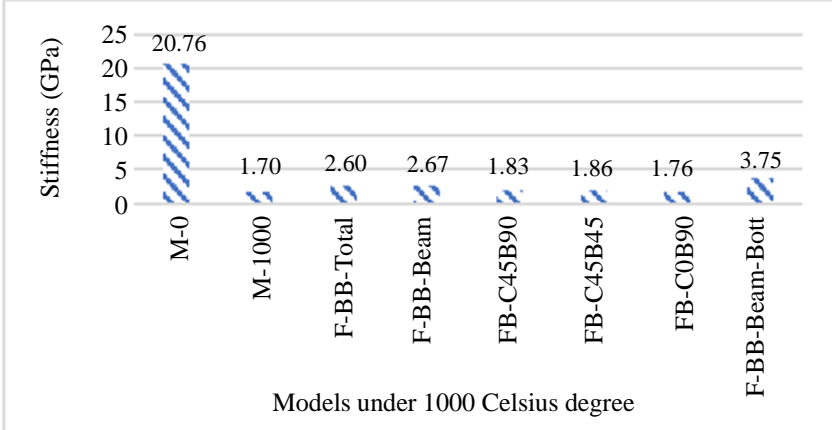

Fig. 31: Comparison of stiffness -1000 Celsius degree

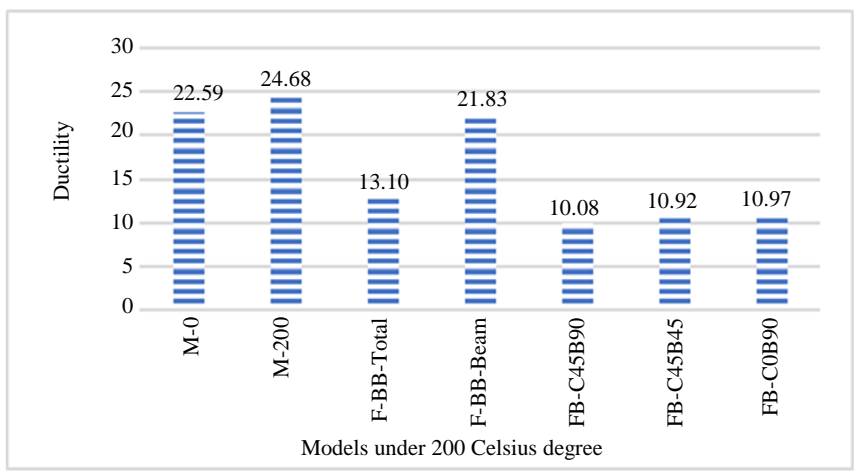

Fig. 32: Comparison of ductility -200 Celsius degree

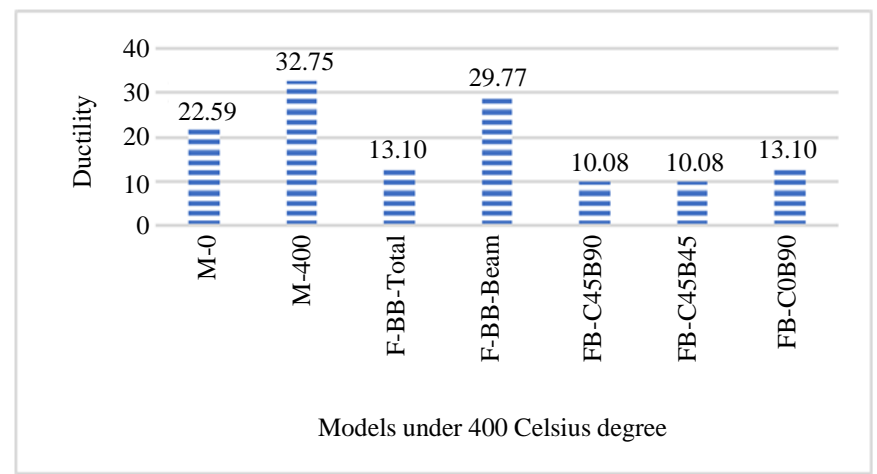

Fig. 33: Comparison of ductility 400 Celsius degree

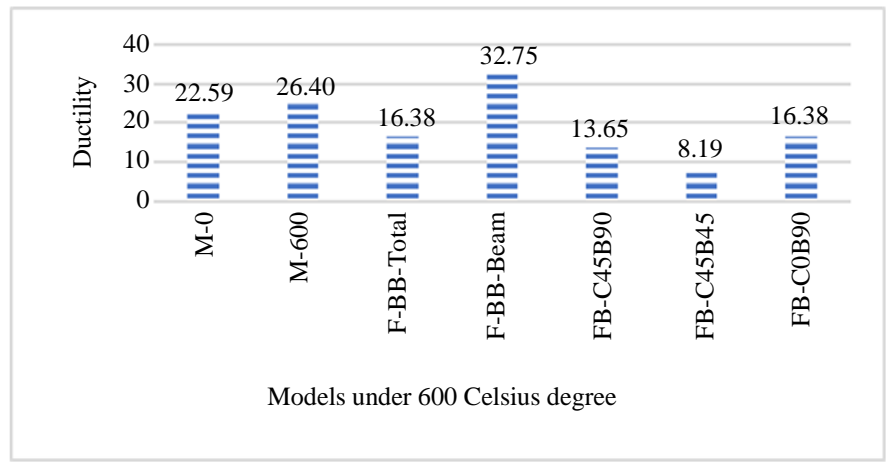

Fig. 34: Comparison of ductility 600 Celsius degree 


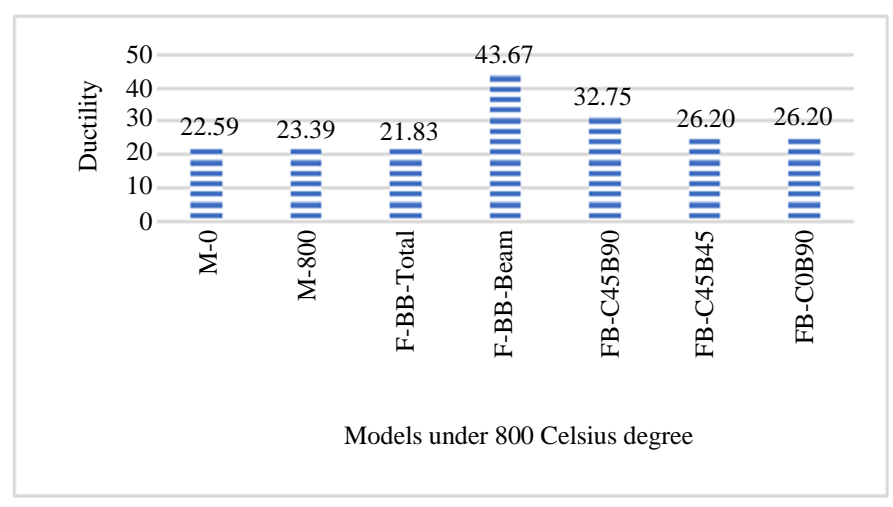

Fig. 35: Comparison of ductility 800 Celsius degree

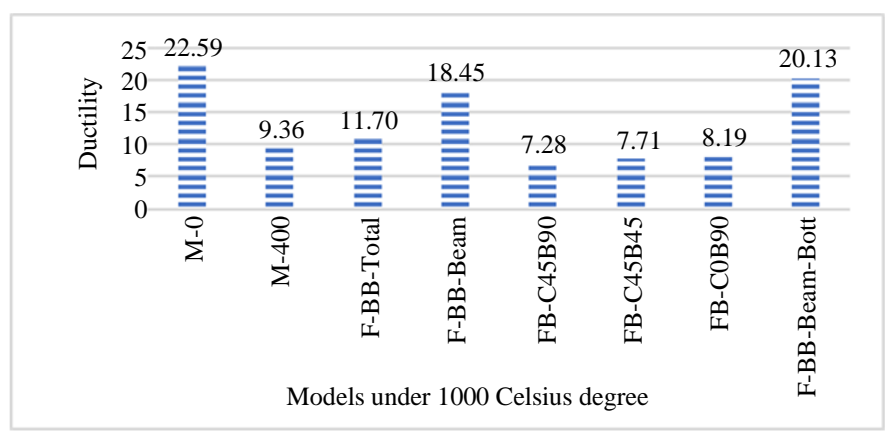

Fig. 36: Comparison of ductility 1000 Celsius degree

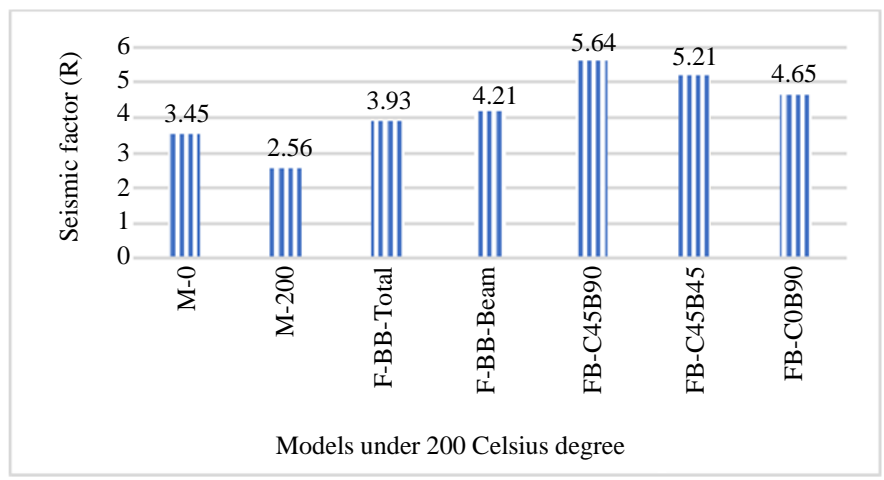

Fig. 37: Comparison of seismic factor- 200 Celsius degree

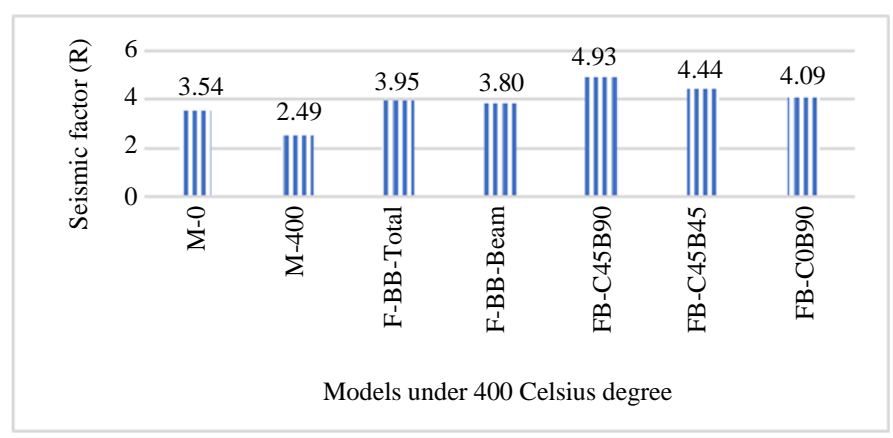

Fig. 38: Comparison of seismic factor- 400 Celsius degree 


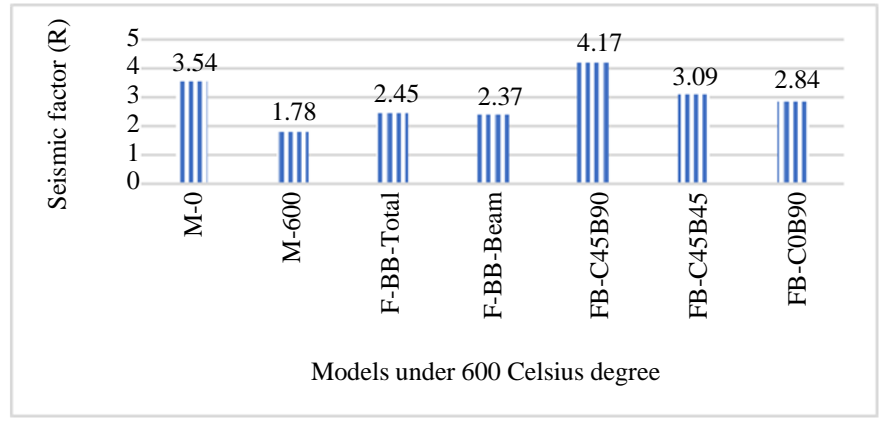

Fig. 39: Comparison of seismic factor- 600 Celsius degree

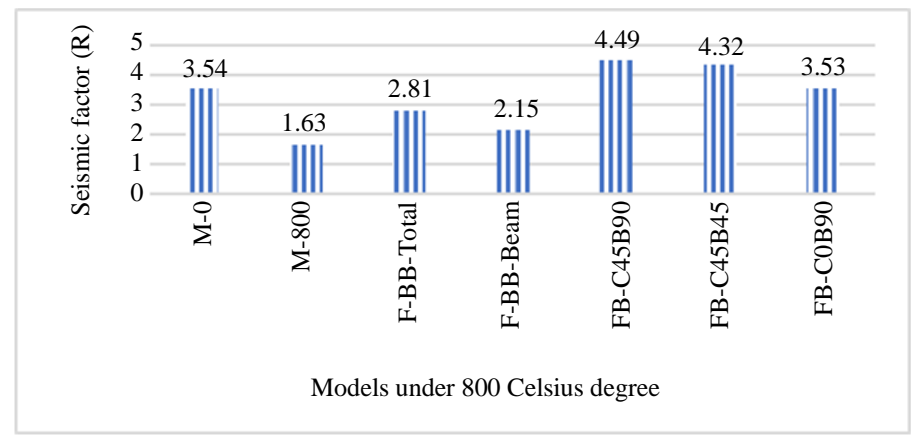

Fig. 40: Comparison of seismic factor- 800 Celsius degree

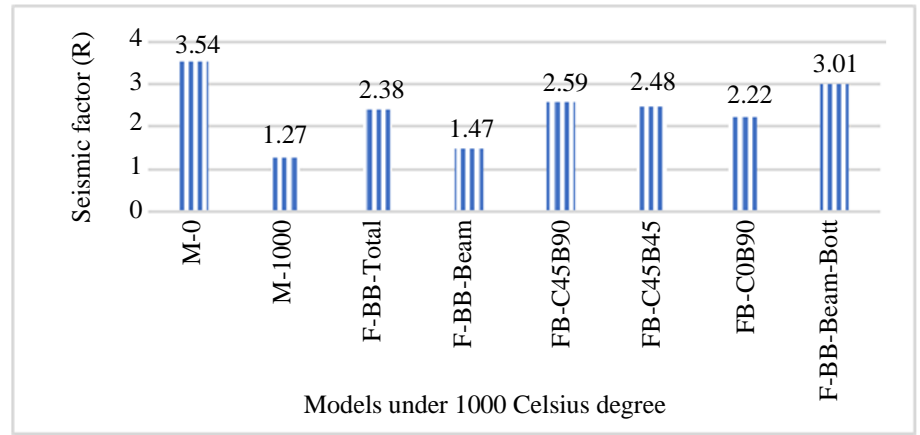

Fig. 41: Comparison of seismic factor- 1000 Celsius degree

\section{Conclusion}

Based on the finite element simulation parametrical studies, the following results are made:

- The retrofitting method with BFRP sheets has better performance in increasing load capacity and FBC45B90 is the best and optimized technique among all other methods.

- Increasing the fire temperature cause reducing of stiffness. However, wrapping with BFRP sheets performs better than reinforcing method. On the other side, using the combination of BFRP and steel can enhance the stiffness in comparison with model with only steel bars.
- Models reinforced with only steel bars has the higher ductility under 200,400 and $600^{\circ} \mathrm{C}$, but after that it has a reducing trend.

- The reinforcing combination which is called now as optimized model (F-BB-Beam) has the highest ductility than other specimens (except model with steel like M-200, M-400, M-600 and M-800) up to $800^{\circ} \mathrm{C}$. Since then (on $1000^{\circ} \mathrm{C}$ ), the F-BB-BeamBott model show the highest ductility factor. It can be concluded that using BFRP bars in tensile are of beam combined with steel in compressive side can significantly improve the ductility of RC frame.

- In seismic factor results, the FB-C45B90 is the best method of retrofitting up to $800^{\circ} \mathrm{C}$ and model with 
only steel bars reduces the seismic factor by increasing the fire load.

- $\quad$ The $\mathrm{RC}$ frame tolerates the fire loading conditions up to $600^{\circ} \mathrm{C}$. Up to this temperature, the retrofitting and reinforcing technique can have positive effect on enhancing the performance of RC frame's behavior. Granted, these techniques still can improve the behavior but, the improvement is too small

\section{Acknowledgment}

The Authors conducted this study is South Tehran Branch, Islamic Azad University, Tehran, Iran.

This research received no specific grant from any funding agency in the public, commercial, or not-forprofit sectors.

The Authors also declare that there is no conflict of interest.

\section{Author's Contributions}

Reza Salehi: Performed modeling with FEM software and data analysis. Also, participated in writing the manuscript.

Abbas Akbarpour: Provided the research topic and guided the research development, experimental plan and data analysis. Also, participated in writing the manuscript.

Armaghan Shalbaftabar: Performed modeling with FEM software and data analysis. Also, participated in writing the manuscript.

\section{Ethics}

This article is original and contains unpublished material. Authors declare that are not ethical issues.

\section{References}

Ahn, Y., Jang, J. G., \& Lee, H.-K. (2016). Mechanical properties of lightweight concrete made with coal ashes after exposure to elevated temperatures. Cement and concrete composites, 72, 27-38.

Asmari, A., Marrero, A., \& Maher, E. (2017). Autonomous Navigation and Geotagging for Concrete Bridge Deck Inspections with the RABIT Robotic Platform. Paper presented at the ASNT Annual Conference 2017.

Bracci, J. M., Kunnath, S. K., \& Reinhorn, A. M. (1997). Seismic performance and retrofit evaluation of reinforced concrete structures. Journal of structural engineering, 123(1), 3-10.

Chandrasekaran, S., Nunziante, L., Serino, G., \& Carannante, F. (2016). Seismic design aids for nonlinear analysis of reinforced concrete structures: CRC press.
Crisafulli, F. J. (1997). Seismic behaviour of reinforced concrete structures with masonry infills.

Fallahi, M., Roudsari, S. S., Abu-Lebdeh, T., \& Petrescu, F. I. (2019). Investigating the effects of frp bars on the seismic behavior of reinforced concrete coupling beams. Independent Journal of Management \& Production, 10(8), 1819-1833.

Fallahi, M., Sayyar Roudari, S., Haghighifar, M., \& Madandoost, R. (2018). Modeling of reinforced concrete frames with Infill walls under cyclic loading Strengthening with CFRP. American Journal of Engineering and Applied Sciences, 11(3), 1086-1099.

Fanaie, N., Esfahani, F. G., \& Soroushnia, S. (2015). Analytical study of composite beams with different arrangements of channel shear connectors. Steel and Composite Structures, 19(2), 485-501.

Gong, J., Zou, X., \& Xia, P. (2019). Experimental Investigation of the Natural Bonding Strength between Stay-In-Place Form and Concrete in FRPConcrete Decks/Beams. Applied Sciences, 9(5), 913.

Hamoush, S., Megri, A., Pasha, R., \& Sayyar Roudsari, S. (2019). Fire Performance of Sustainable Materials Made from Renewable Sources. Paper presented at the 4th International Sustainable Buildings Symposium, Dallas, USA.

Hamoush, S., Salah M, A., Shalbaftabar, A., Sayyar Roudsari, S., \& C. Megri, A. (2020). In-Plane Performance of Nonstructural Partition Wall Systems under Cyclic Load Conditions. Paper presented at the 9th Turkish Conference on Earthquake Engineering (9TCEE), Turkey.

Hemmati, A., Kheyroddin, A., Sharbatdar, M., Park, Y., \& Abolmaali, A. (2016). Ductile behavior of high performance fiber reinforced cementitious composite (HPFRCC) frames. Construction and Building Materials, 115, 681-689.

Huo, J., Liu, H., \& Xu, X. (2018). Effects of long-term loading on fire-damaged reinforced-concrete stub columns. Magazine of Concrete Research, 71(9), 476-487.

ISO. (2019). ISO 834. In Fire-resistance tests -- elements of building construction: ISO.

Jiang, C. J., Yu, J. T., Li, L. Z., Wang, X., Wang, L., \& Liao, J. H. (2018). Experimental study on the residual shear capacity of fire-damaged reinforced concrete frame beams and cantilevers. Fire Safety Journal, 100, 140-156.

Khaliq, W., \& Kodur, V. (2017). Effectiveness of polypropylene and steel fibers in enhancing fire resistance of high-strength concrete columns. Journal of structural engineering, 144(3), 04017224.

Kheyroddin, A., \& Naderpour, H. (2008). Nonlinear finite element analysis of composite RC shear walls. Iranian Journal of Science and Technology, 32(B2), 79. 
Kodur, V., \& Agrawal, A. (2016). An approach for evaluating residual capacity of reinforced concrete beams exposed to fire. Engineering Structures, 110, 293-306.

Kodur, V., Bhatt, P., \& Naser, M. (2019). High temperature properties of fiber reinforced polymers and fire insulation for fire resistance modeling of strengthened concrete structures. Composites Part B: Engineering, 175, 107104.

Kodur, V., Garlock, M., \& Iwankiw, N. (2012). Structures in fire: state-of-the-art, research and training needs. Fire Technology, 48(4), 825-839.

Lenwari, A., Rungamornrat, J., \& Woonprasert, S. (2016). Axial compression behavior of fire-damaged concrete cylinders confined with CFRP sheets. Journal of composites for construction, 20(5), 04016027.

Li, J., Wu, C., \& Hao, H. (2015). Investigation of ultrahigh performance concrete slab and normal strength concrete slab under contact explosion. Engineering Structures, 102, 395-408.

Li, L. Z., Liu, X., Yu, J. T., Lu, Z. D., Su, M. N., Liao, J. H., \& Xia, M. (2019a). Experimental study on seismic performance of post-fire reinforced concrete frames. Engineering Structures, 179, 161-173.

Li, Z., Liu, Y., Huo, J., \& Elghazouli, A. Y. (2019b). Experimental and analytical assessment of RC joints with varying reinforcement detailing under pushdown loading before and after fires. Engineering Structures, 189, 550-564.

Li, X., Xu, Z., Bao, Y., \& Cong, Z. (2019c). Post-fire seismic behavior of two-bay two-story frames with high-performance fiber-reinforced cementitious composite joints. Engineering Structures, 183, 150-159.

Lim, R. S., La, H. M., \& Sheng, W. (2014). A robotic crack inspection and mapping system for bridge deck maintenance. IEEE Transactions on Automation Science and Engineering, 11(2), 367-378.

Liu, J. C., Tan, K. H., \& Yao, Y. (2018). A new perspective on nature of fire-induced spalling in concrete. Construction and Building Materials, 184, 581-590.

Ma, Q., Guo, R., Zhao, Z., Lin, Z., \& He, K. (2015). Mechanical properties of concrete at high temperatureâ€”A review. Construction and Building Materials, 93, 371-383.

Mistri, A., Davis, P., \& Sarkar, P. (2016). Condition assessment of fire affected reinforced concrete shear wall buildingâ€"A case study. Adv. Concr. Constr, 4(2), 89-105.

Qin, R., Lau, D., Tam, L.-h., Liu, T., Zou, D., \& Zhou, A. (2019). Experimental investigation on interfacial defect criticality of FRP-confined concrete columns. Sensors, 19(3), 468.
Raouffard, M. M., \& Nishiyama, M. (2016). Residual load bearing capacity of reinforced concrete frames after fire. Journal of Advanced Concrete Technology, 14(10), 625-633.

Roudsari, S. S., Hamoush, S. A., Soleimani, S. M., \& Madandoust, R. (2019). Evaluation of large-size reinforced concrete columns strengthened for axial load using fiber reinforced polymers. Engineering Structures, 178, 680-693.

Roudsari, S. S., \& Abu-Lebdeh;, T. M. (2019). Evaluation of Fire Effects on Reinforced Concrete Columns Using Finite Element Method. American Journal of Engineering and Applied Sciences, 12(2), 227-235.

Sasmal, S., Ramanjaneyulu, K., NovJk, B., Srinivas, V., Kumar, K. S., Korkowski, C., . . Iyer, N. R. (2011). Seismic retrofitting of nonductile beam-column subassemblage using FRP wrapping and steel plate jacketing. Construction and Building Materials, 25(1), 175-182.

Sayyar Roudsari, S., Hamoush, S., Soleimani, S., AbuLebdeh, T., \& HaghighiFar, M. (2018). Analytical study of reinforced concrete beams strengthened by FRP bars subjected to impact loading conditions. American Journal of Engineering and Applied Sciences, 11(2), 407-425.

Sayyar Roudsari, S., Hamoush, S., Szeto, T., \& Yi, S. (2019a). Using a 3D Computer Vision System for Inspection of Reinforced Concrete Structures. In Science and Information (pp. 608-618). Las Vegas: Springer.

Sayyar Roudsari, S., Okore-Hanson, T., Hamoush, S., Younho, S., Yi , S., Taylor, S., \& Plummer, J. (2019b). Robotic Non-destructive Test of Concrete Structures with GPR, Impact Echo and 3D Vision. Paper presented at the WM Symposia 2019 Conference, Phoenix, USA.

Sayyar Roudsari, S., Okore-Hanson, T., Hamoush;, S. A., Sun, Y., \& Ahmed, M. (2019c). Robotic Nondestructive Evaluation of RC Structures Using 3D Vision Camera, IE and GPR. Paper presented at the American Society for Nondestrctive Testing

Sayyar Roudsari, S., Okore-Hanson, T., Hamoush, S., Yi, S., \& Younho, S. (2020a). GPR Robotic Assisted Non-Destructive Evaluation of Concrete Structures. Paper presented at the WM Symposia, Phoenix, AZ.

Sayyar Roudsari, S., Shalbaftabar, A., Abu-Lebdeh, T., Megri, A., \& Hamoush, S. (2020b). Investigation of Sandwich Panel Under High Temperature Loading Using Finite Element Analysis. American Journal of Engineering and Applied Sciences, 13(2), 318-326.

Shah, A. H., \& Sharma, U. (2017). Fire resistance and spalling performance of confined concrete columns. Construction and Building Materials, 156, 161-174. 
Soleimani, S. M., Boyd, A. J., Komar, A. J., \& Roudsari, S. S. (2019). Fatigue in Concrete under Low-Cycle Tensile Loading Using a Pressure-Tension Apparatus. Applied Sciences, 9(16), 3217.

Soleimani, S. M., \& Sayyar Roudsari, S. (2015). Analytical study of reinforced concrete beams tested under impact loading. Paper presented at the Proceedings of the 4th International Workshop Performance Protection Strengthening Structures Under Extreme Loading, East Lansing, MI, USA,.

Soleimani, S. M., \& Sayyar Roudsari, S. (2019). Analytical Study of Reinforced Concrete Beams Tested under Quasi-Static and Impact Loadings. Applied Sciences, 9(14), 2838.

Soroushnia, S., Tafreshi, S. T., Omidinasab, F., Beheshtian, N., \& Soroushnia, S. (2011). Seismic performance of RC elevated water tanks with frame staging and exhibition damage pattern. Procedia Engineering, 14, 3076-3087.

Tang, T., \& Saadatmanesh, H. (2003). Behavior of concrete beams strengthened with fiber-reinforced polymer laminates under impact loading. Journal of composites for construction, 7(3), 209-218.
Wang, Y. C., Wong, P., \& Kodur, V. (2007). An experimental study of the mechanical properties of fibre reinforced polymer (FRP) and steel reinforcing bars at elevated temperatures. Composite structures, 80(1), 131-140.

Yi, W. J., He, Q. F., Xiao, Y., \& Kunnath, S. K. (2008). Experimental study on progressive collapse-resistant behavior of reinforced concrete frame structures. ACI Structural Journal, 105(4), 433.

Zhang, H. Y., Kodur, V., Wu, B., Cao, L., \& Wang, F. (2016). Thermal behavior and mechanical properties of geopolymer mortar after exposure to elevated temperatures. Construction and Building Materials, $109,17-24$.

Zhang, X., Kunnath, S., \& Xiao, Y. (2017). Experimental study of reinforced concrete columns damaged by fire following an earthquake. The 2017 World Congress on Advance in Structural Engineering and Mechanics, ASEM.

Zhou, J., \& Wang, L. (2019). Repair of fire-damaged reinforced concrete members with axial load: a review. Sustainability, 11(4), 963. 